\title{
Selective Vitamin D Receptor Modulators (SVIMS) as Potential Adjuvant Therapeutic Agents
}

\section{Wei Li*}

Associate Professor, Department of Pharmaceutical Sciences, University of Tennessee Health Science Center, USA

Vitamin D3 (cholecalciferol, D3) is one of the most important forms of vitamin D in human health [1-4]. There are two sources for human beings to obtain vitamin D3. The first source is the conversion of 7-dehydrocholesterol (7-DHC) in the skin to pre-vitamin D3 by UVB irradiation from the sunlight, followed by thermal isomerization to produce vitamin D3 (Figure 1) [5]. This is a tightly regulated process by the human body, and it is impossible to result in vitamin D3 overdose. The second source is through diet supplements. Human body cannot regulate this source of intake well, and vitamin D3 overdose and subsequent toxicity could occur. Interestingly, vitamin D3 itself is not the biologically active form. It must be first hydroxylated at the C25 position in the liver to produce 25-hydroxyvitamin D3 (25(OH)D3), followed by a second hydroxylation at the $\mathrm{C} 1$ position in the kidney or by monocyte-macrophages in the immune system to produce the biologically active form 1,25-dihydroxyvitamin D3 (1,25(OH) $\mathrm{D} 3)$ (Figure 1). 1,25(OH) $)_{2} \mathrm{D} 3$ binds to the Vitamin D Receptor (VDR) which ultimately lead to its various biological functions (Figure 1).

Apart from their classical action of regulating bone health and calcium homeostasis, there are accumulating evidence in the literature suggesting that vitamin D3 also have non-classical actions including strong inhibition of cell proliferation, promotion of cell differentiation, and suppression of inflammation responses [5-8]. However, the use of $1,25(\mathrm{OH})_{2} \mathrm{D} 3$ at its effective dose is often limited by its severe hypercalcemic side effect in which calcium concentrations in serum reaches dangerously high levels (>10.5 mg/dL) [9]. The high concentration of circulating calcium could deposit in software tissues such as heart, liver, and kidney, and could ultimately result in tissue calcifications [9].

There have been tremendous efforts in both industry and academia to develop new vitamin D3 analogs that can retain the beneficial effects but have minimal or absence of the undesired hypercalcemic side effects, for a variety of potential indications such as cancer and inflammation [8,10-16]. Many potent vitamin D receptor ligands have been discovered or synthesized, and several made to clinical trials (examples are shown in Figure 2).While Zemplar is an approved drug used to treat secondary hyperparathyroidism (over activity of the parathyroid gland) in people with chronic kidney failure, at present, however, there are no FDA approved vitamin D3 analogs that can be used safely to effectively treat cancer or inflammation disorders (Figure 2).

Traditionally most of the new vitamin D3 analogs reported in the literature can be classified as "super VDR agonists", that is, a compound has significantly higher affinity in binding to the VDR than its natural ligand $1,25(\mathrm{OH})_{2} \mathrm{D} 3$. The rationale is that just a tiny amount of the compound will be required to activate the VDR to produce the desired biological function, without reaching the higher concentration which may lead to hypercalcemia [8]. This is a valid approach, but it also has its limitations. Another approach recently proposed by researchers including our labs is based on the hypothesis that desired tissue-selectivity, rather than the absolute binding affinity to the VDR, hold the key to develop new generations of clinically useful vitamin D3 analogs. In fact, VDR belongs to nuclear receptor families, and it is well known that many therapeutically useful ligands for some of these nuclear receptors have excellent tissue-selectivity. Two examples are Selective Androgen Receptor Modulators (SARMs) [17-19] and Selective Estrogen Modulators (SERMs) [20-23]. Therefore, similar to SARMs and SERMs, it should be possible to develop Selective Vitamin D Receptor Modulators (SVIMs). While there are many types of potential tissue-selectivity can be defined for different therapeutic indications, one promising tissue-selectivity is the selective VDR activation in immune cells over in intestine cells. VDR activation in the immune cells is responsible for its strong suppression of inflammation responses, while VDR activation in the intestine cells is responsible for the undesired hypercalcemic side effects. If a SVIM selectively activates the VDR in the immune cells over the intestine cells, such an agent will likely to be very useful in treating a variety of immune diseases such as arthritis for which more effective therapies are urgently needed given the increasing lifespan of populations, especially in the developed countries. It is also helpful to realize that for some diseases such as cancer and chronic inflammations, it may not be realistic to use a single agent for very effective treatment; therefore, a rationally designed drug combination treatment strategy in which a SVIM serving as an adjuvant agent adding to the standard treatment may provide the best benefits for patients.

Currently there are several hurdles researchers need to overcome in order to facilitate the development of clinically useful SVIMs. First, we need a clear understanding of molecular mechanisms leading to the desired tissue-selectivity. Several potential reasons can lead to the tissue-selectivity, including VDR polymorphism, differential distribution/functions of VDR in different tissues, alternative targets for SVIMs, different downstream responses from VDR, etc. Availability for such information will be tremendously helpful in this drug discovery process. Second, relatively easy and reliable in vitro assay methods that can reasonably predict the in vivo responses for SVIMs will be very useful. Calcium absorption in the intestines and the immune functions are extremely complicated process. While in vivo experiments will be the best predictor, they may not be very practical in screening a large number of potential SVIMs. Developing reliable in vitro assays will facilitate this area of research substantially. In summary, while there are indeed significant challenges faced by developing clinically useful SVIMs, it also provides rich opportunities to advance the science for this area of research.

*Corresponding author: Wei Li, Associate Professor, Department of Pharmaceutical Sciences, College of Pharmacy, University of Tennessee Health Science Center, Memphis, TN 38163, USA, Tel: 901-448-7532; Fax: 901-448-6828; E-mail: wli@uthsc.edu

Received March 27, 2013; Accepted May 02, 2013; Published May 06, 2013

Citation: Li W (2013) Selective Vitamin D Receptor Modulators (SVIMS) as Potential Adjuvant Therapeutic Agents. Mod Chem appl 1: e110. doi:10.4172/2329-6798.1000e110

Copyright: (c) 2013 Li W. This is an open-access article distributed under the terms of the Creative Commons Attribution License, which permits unrestricted use, distribution, and reproduction in any medium, provided the original author and source are credited. 


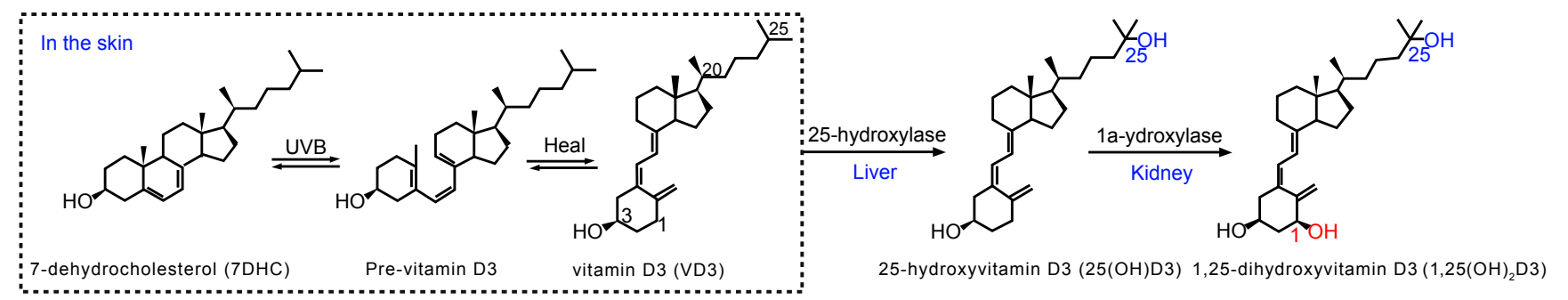

Figure 1: Generation of vitamin D3 from 7-DHC in the skin and the activation of vitamin D3 to its biologically active form $1,25(\mathrm{OH})_{2} \mathrm{D} 3 \mathrm{in}$ the human body.

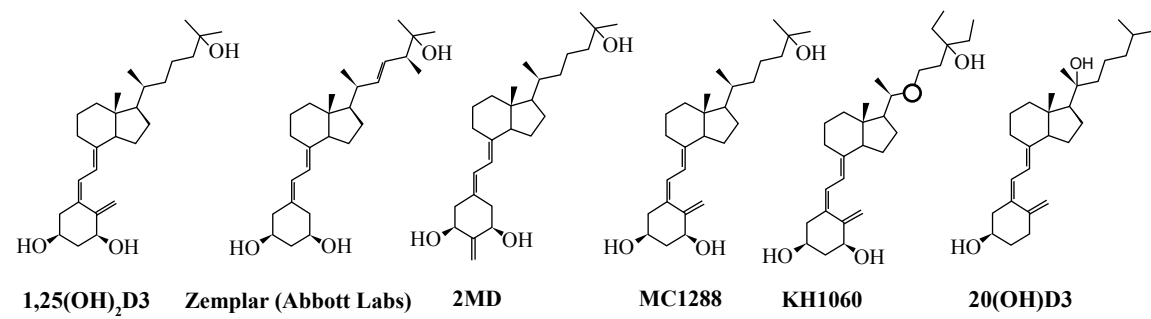

Figure 2: Examples of existing potent VDR ligands and their structural comparison to the VDR native ligand, $1,25(\mathrm{OH})_{2} \mathrm{D} 3$.

\section{References}

1. Girgis CM, Clifton-Bligh RJ, Hamrick MW, Holick MF, Gunton JE (2013) The roles of vitamin D in skeletal muscle: form, function, and metabolism. Endocr rev 34: 33-83.

2. Pilz S, Tomaschitz A, Marz W, Drechsler C, Ritz E, et al. (2011) Vitamin D, cardiovascular disease and mortality. Clin Endocrinol (Oxf) 75: 575-584.

3. Holick MF (2011) Vitamin D: a d-lightful solution for health. J Investig Med 59 872-880.

4. Deluca GC, Kimball SM, Kolasinski J, Ramagopalan SV, Ebers GC (2013) The Role of Vitamin D in Nervous System Health and Disease. Neuropathol App Neurobiol

5. Deeb KK, Trump DL, Johnson CS (2007) Vitamin D signalling pathways in cancer: potential for anticancer therapeutics. Nat Rev Cancer 7: 684-700.

6. Masuda S, Jones G (2006) Promise of vitamin D analogues in the treatment of hyperproliferative conditions. Mol Cancer Ther 5: 797-808.

7. Pinette KV, Yee YK, Amegadzie BY, Nagpal S (2003) Vitamin D receptor as a drug discovery target. Mini Rev Med Chem 3: 193-204.

8. Takahashi T, Morikawa K (2006) Vitamin D receptor agonists: opportunities and challenges in drug discovery. Curr Top Med Chem 6: 1303-1316.

9. Carroll MF, Schade DS (2003) A practical approach to hypercalcemia. Am Fam Physician 67: 1959-1966.

10. Larsson P, Mattsson L, Klareskog L, Johnsson C (1998) A vitamin D analogue (MC 1288) has immunomodulatory properties and suppresses collageninduced arthritis $(\mathrm{CIA})$ without causing hypercalcaemia. Clin Exp Immunol 114 277-283

11. Yang W, Freedman LP (1999) 20-Epi analogues of 1,25-dihydroxyvitamin D3 are highly potent inducers of DRIP coactivator complex binding to the vitamin D3 receptor. J Biol Chem 274: 16838-16845.

12. Yee YK, Chintalacharuvu SR, Lu J, Nagpal S (2005) Vitamin D receptor modulators for inflammation and cancer. Mini Rev Med Chem 5: 761-778.

13. Inaba Y, Yoshimoto N, Sakamaki Y, Nakabayashi M, Ikura T, et al. (2009) A new class of vitamin $D$ analogues that induce structural rearrangement of the ligandbinding pocket of the receptor. J Med Chem 52: 1438-1449.

14. Janjetovic Z, Zmijewski MA, Tuckey RC, DeLeon DA, Nguyen MN, et al. (2009) 20-Hydroxycholecalciferol, product of vitamin D3 hydroxylation by P450scc decreases NF-kappaB activity by increasing IkappaB alpha levels in human keratinocytes. PloS One 4: e5988.

15. Na S, Ma Y, Zhao J, Schmidt C, Zeng QQ, et al. (2011) A Nonsecosteroidal Vitamin D Receptor Modulator Ameliorates Experimental Autoimmune Encephalomyelitis without Causing Hypercalcemia. Autoimmune Dis.

16. Lu Y, Chen J, Janjetovic Z, Michaels P, Tang EK, et al. (2012) Design, synthesis, and biological action of 20R-hydroxyvitamin D3. J Med Chem 55: 3573-3577.

17. Yarrow JF, Conover CF, McCoy SC, Lipinska JA, Santillana CA, et al. (2011) 17-Hydroxyestra-4,9,11-trien-3-one (trenbolone) exhibits tissue selective anabolic activity: effects on muscle, bone, adiposity, hemoglobin, and prostate. Am J Physiol Endocrinol Metab 300: E650-660.

18. Clarke BL, Khosla S (2009) New selective estrogen and androgen receptor modulators. Curr Opin Rheumatol 21: 374-379.

19. Mohler ML, Bohl CE, Jones A, Coss CC, Narayanan R, et al. (2009) Nonsteroidal selective androgen receptor modulators (SARMs): dissociating the anabolic and androgenic activities of the androgen receptor for therapeutic benefit. J Med Chem 52: 3597-3617.

20. Silverman SL (2010) New selective estrogen receptor modulators (SERMs) in development. Curr Osteoporos Rep 8: 151-153.

21. Pickar JH, Mirkin S (2010) Tissue-selective agents: selective estrogen recepto modulators and the tissue-selective estrogen complex. Menopause Int 16: 121 128.

22. Arevalo MA Santos-Galindo M, Lagunas N, Azcoitia I, Garcia-Segura LM (2011) Selective estrogen receptor modulators as brain therapeutic agents. $J$ Mol Endocrinol 46: R1-9.

23. 23. Rosano C, Stec-Martyna E, Lappano R, Maggiolini M (2011) Structurebased approach for the discovery of novel selective estrogen receptor modulators. Curr Med Chem 18: 1188-1194. 